Article

\title{
Effect of Pheromones, Plant Volatiles and Spinosad on Mating, Male Attraction and Burrowing of Cadra cautella (Walk.) (Lepidoptera: Pyralidae)
}

\author{
Abeysinghe M. P. Sammani ${ }^{1}$, Dissanayaka M. S. K. Dissanayaka ${ }^{1}$, Leanage K. W. Wijayaratne ${ }^{1, *}$, \\ Thushara C. Bamunuarachchige ${ }^{2}$ (D) and William R. Morrison III ${ }^{3}$ (D) \\ 1 Department of Plant Sciences, Faculty of Agriculture, Rajarata University of Sri Lanka, Puliyankulama, \\ Anuradhapura 50000, Sri Lanka; prabodha12sammani@gmail.com (A.M.P.S.); \\ dissanayaka.randeniya@gmail.com (D.M.S.K.D.) \\ 2 Department of Bioprocess Technology, Faculty of Technology, Rajarata University of Sri Lanka, Mihintale, \\ Anuradhapura 50000, Sri Lanka; heroiraj@gmail.com \\ 3 USDA Agricultural Research Service, Center for Grain and Animal Health Research, 1515 College Ave., \\ Manhattan, KS 66052, USA; william.morrison@usda.gov \\ * Correspondence: wollylk@yahoo.com
}

Received: 22 September 2020; Accepted: 25 November 2020; Published: 28 November 2020

Simple Summary: Sex pheromones used at higher concentrations than their availability in insects have been successful in decreasing the insect population. Furthermore, botanical oils have also had negative impacts on the insect population level. In the first study, we investigated the combined effect of sex pheromones and plant oils on mating of almond moth. The second study sought the burrowing ability of almond moth larvae through different flour media. Mating declined on the presence of pheromones and botanical oils, whereas burrowing ability differed with flour type. Exposure to spinosad affected both mating success and larval penetration through flour media. The findings of this study reveal that various applications of sex pheromones, plant oils and spinosad ensure the better protection of cereal-based agricultural produce from insect infestation during storage.

Abstract: Mating disruption of Cadra cautella (Walk.) (Lepidoptera: Pyralidae) using its sex pheromone components, (Z, E)-9,12-tetradecadienyl acetate (ZETA) and (Z)-9-tetradecadien-1-yl acetate (ZTA), is successful in its population management. In addition, botanical oils have extensively been investigated in stored product pest management, but the effect of synthetic sex pheromones on the mating of C. cautella in the presence of plant volatiles is still unknown. Spinosad is used in food facilities as a contact insecticide but, if $C$. cautella larvae burrow into food, they may escape from spinosad. Importantly, the impact of spinosad on burrowing ability of C. cautella remains unknown. Therefore, the objectives of this study were to determine the effects of sex pheromone components ZETA and ZTA in the presence of botanical oils on the mating of $C$. cautella and the burrowing ability of $C$. cautella larvae in different types of flour treated with spinosad. In the first study, male and female moths were introduced into the cubicle having botanical oils and pheromone components. The mating status of female moths and male moth attraction to the trap was determined. The control experiments had only the botanical oils or pheromones. In the second study, burrowing ability of C. cautella larvae through different flour types was evaluated over $10 \mathrm{~d}$. The flour was sprayed with spinosad (treatments) or water (controls). The mating success was higher with botanical oils alone but declined with exposure to pheromone either alone or combined with botanical oils. No differences in male attraction to traps were observed in botanical only, pheromone only or pheromone + botanical oil treatments. The burrowing of $C$. cautella larvae differed with flour type and spinosad altered burrowing ability. Thus, we conclude that the mating and burrowing of $C$. cautella is influenced by its pheromone and by exposure to botanicals and spinosad. 
Keywords: Cadra cautella mating disruption; sex pheromone; botanicals; burrowing; spinosad

\section{Introduction}

There is an increasing demand for food due to the rapid increase of world population by 83 million people every year [1]. Post-harvest protection of cultivated food crops is an essential component to cater this food requirement. Indeed, post-harvest losses of agricultural commodities are very high, as up to $1 / 3$ of the commodities produced are lost annually across the world, which amounts to 1.3 billion tons of food [2]. Insects are a major cause of deterioration of stored food, which may even be higher in tropical locations [3]. In Sri Lanka, serious losses due to insect infestation are reported for stored grains [4-6], rice flour [7], spices [8] and animal feed [9].

Cadra cautella (Walk.) (Lepidoptera: Pyralidae) is an important pest for storage losses in Sri Lanka [10] and other countries [11-13]. It damages grains and grain-based products, pulses, dried fruits, nuts, spices, cocoa beans and confectionaries [11,13-18]. The common control methods used for C. cautella and other stored-product insects are typically contact insecticides [19], fumigants [20-22], high temperature [23], and aeration practices [24]. Despite the success of these methods, each has its own drawbacks, which may variously include insecticide toxicity, health hazards to workers [25], non-target effects on the environment [26,27] and the development of resistance in insects [28]. Therefore, there has been a push to develop biorational pest management methods in the postharvest supply chain $[27,29-31]$.

Monitoring and suppressing insect populations are important parts of integrated pest management program (IPM) [32-34]. Most often, pheromone traps and mating disruption are used to monitor and control the population of $C$. cautella [35-37]. Female moths of $C$. cautella release the two-component sex pheromone, (Z, E)-9,12-tetradecadienyl acetate (ZETA) and (Z)-9-tetradecadien-1-yl acetate (ZTA) in a natural 14:1 ratio [38]. ZETA is the major component and ZTA is a synergist of ZETA [39]. The synthetic form of ZETA is commercially available and used in traps for monitoring C. cautella $[15,40,41]$. Recent studies on different uses of $C$. cautella pheromones and its implications for behavioral manipulation [42] have augmented the information available to food facility managers in Sri Lanka to support the use of this technology in IPM programs.

Botanical compounds have extensively been investigated for application in stored-product insect pest management. Many studies have documented the ability of botanical insecticides to induce mortality, repellency, and other behavioral changes in stored-product insects [43-50]. In fact, some of the prior work has specifically evaluated the direct effects of botanical compounds on C. cautella [51,52]. However, despite the work evaluating the effect of botanicals on C. cautella and the extensive amount of research conducted on different uses of pheromone components of $C$. cautella $[15,42]$, there have been few studies elucidating the potentially synergistic effects of using pheromones and plant volatiles (e.g., with botanical oils as a surrogate) on C. cautella mating disruption. However, it is reported that the rise of systems-level thinking in agriculture has resulted in significant innovation in food production [53]. Thus, it is increasingly important not just to evaluate individual tactics independently of each other, but in combination, to deliver a fuller understanding of postharvest pest management systems.

In C. cautella, larvae feed on durable goods and contribute to contamination, decreasing the quality of commodities to unacceptable levels for human consumption [16]. Though anecdotally it is known that $C$. cautella frequently burrow, there has been little formal study of this behavior in food sources [54]. Lack of knowledge on the burrowing ability of C. cautella may lead to inaccurate predictions of population development after exposure to contact insecticides, as larvae may be able to escape exposure in refugia found beneath the surface of food sources.

One potential contact insecticide that may affect burrowing of C. cautella is spinosad. Spinosad is a biorational, reduced-risk insecticide developed from the bacterium Saccharopolyspora spinosa [55]. It is effective at controlling mature and immature stages of various stored-product insect species [3,56-59]. 
Spinosad has also shown promise in controlling C. cautella [57]. However, the effect of exposure of C. cautella larvae to spinosad and its effect on burrowing ability has not been investigated. Therefore, the objectives of this study were to determine the effect of sex pheromone components with or without botanical oils on the mating of $C$. cautella moths, and to determine the burrowing ability of C. cautella larvae in different types of flour treated with spinosad or water.

\section{Materials and Methods}

\subsection{Insect Cultures}

The laboratory culture of C. cautella was established using adult moths collected from a rice milling center at Puliyankulama, Anuradhapura, Sri Lanka. The adult insects were introduced to rice flour medium in a $5 \mathrm{~L}$ plastic bottle with a perforated lid (50 adults on $250 \mathrm{~g}$ of rice flour). These C. cautella cultures were kept inside an incubator with complete darkness (FH-1200 LED T8, HiPoint Laboratory, Taiwan) at a constant $33 \pm 1^{\circ} \mathrm{C}$ temperature and a $60 \pm 5 \%$ relative humidity.

\subsection{Experiment 1. Response of Cadra cautella to Sex Pheromone Components (Z,E)-9, 12-tetradecadienyl} Acetate (ZETA) and (Z)-9-tetradecadien-1-yl Acetate (ZTA) in the Presence of Botanicals

\subsubsection{Preparation of Adults}

Cadra cautella adults were sexed during the pupal stage by referring to the two nodes present on the ventral side of the 8th segment of male pupa under a dissecting microscope (OPTIKA, Triace, Italy) [60]. Individual male and female pupae were placed in separate plastic bottles $(3.6 \mathrm{~cm}$ diameter and $6.2 \mathrm{~cm}$ height) containing $5 \mathrm{~g}$ of rice flour. These adults emerged in the bottles and were used in the experiments.

\subsubsection{Cubicle Construction}

Four cubicles $(1.5 \mathrm{~m} \times 1.5 \mathrm{~m} \times 1.5 \mathrm{~m}$ length:width:height) were constructed using metal frames. The top, bottom and two opposite sides of each cubicle were covered by transparent polythene $(25 \mathrm{~mm}$ thickness). The remaining two opposite sides of each cubicle were covered using an insect proof net (mesh size: 300 holes $/ \mathrm{cm}^{2}$ ) to allow exchange of air from inside the cubicle and the outside environment. Velcro (Garment Accessories.lk, Rajagiriya, Sri Lanka) was used to attach the polythene and net to the cubicle.

\subsubsection{Preparation of Pheromone Blend}

The pheromone blend of ZETA: ZTA used in this study was 5:1, which demonstrated the highest mating disruption in prior work [42]. The pheromone blend was prepared by diluting a commercially available neat stock solutions of ZETA $(100 \%)(100 \mu \mathrm{L})$ and ZTA $(100 \%)(20 \mu \mathrm{L})$ (Insects Ltd. Inc., Westfield, NJ, USA) in hexane $(100 \mu \mathrm{L})$ using a micropipette (Labnet International Inc., Poland) [60]. Four replicate pheromone solutions were prepared. The loading rate of $90 \mathrm{mg}$ of ZETA per dispenser approached the commercial standard loading rate of $160 \mathrm{mg}$ in Cidetrak ${ }^{\mathrm{TM}}$ mating disruption dispensers (Trece, Inc., Adair, OK, USA) [61], and reflected concentrations used in analogous work in the recent past for continuity [42].

\subsubsection{Botanical Oils}

The following botanical oils were used: camphor oil (Cinnamomum camphora), sandalwood oil (Santalum album), neem oil (Azadirachta indica), cinnamon oil (Cinnamomum verum), citronella oil (Cymbopogon nardus) and mee oil (Madhuca longifolia) (LBK Aushadalaya, Anuradhapura, Sri Lanka). Neat $2 \mathrm{~mL}$ of each botanical oil was measured by using a micropipette (Labnet International Inc., Edison, NJ, USA) and added into separate plastic bottles $(3.6 \mathrm{~cm}$ diameter and $6.2 \mathrm{~cm}$ height). 


\subsubsection{Introduction of Botanical Oils and Pheromone Blend into the Cubicle}

The plastic bottle containing the botanical oil was placed at the middle of the bottom side of the cubicle. In the control experiment 1, the cubicle contained the botanical oil alone (no pheromone components). In the control experiment 2, the cubicle contained only the pheromone blend (without botanical oils). A mixture consisting a total of $120 \mu \mathrm{L}$ of ZETA and ZTA pheromone components (in a 5:1 ratio as described above) was added to a triangular proprietary, slow-release filter paper $\left(8 \mathrm{~cm}^{2}\right)$ (Trece, Inc., Adair, OK, USA) and attached to a piece of rigiform using a needle, which was then placed on a Petri dish $(80 \times 15 \mathrm{~mm})$. The Petri dish was located inside a monitoring trap (Storgard ${ }^{\circledR} \mathrm{kit}$ insect monitoring system, Trece Inc., Adair, OK, USA), which was hung from the center suspended $75 \mathrm{~cm}$ distance from the top [62]. Finally, the treatment trials contained both botanical oils and the pheromone blend placed in the same manner as described above in the control experiments. Three hours following the placement of the botanicals, pheromone blend, or both inside the cubicle, the moths were introduced. The four replicates of a particular experiment were conducted using the four cubicles at the same time. The experiments using four replicates of botanical only (six botanicals); pheromone only and botanical + pheromone treatment categories were conducted separately.

\subsubsection{Introduction of Cadra cautella Moths to the Cubicle}

The experiment was conducted using 4 cubicles in a completely randomized design (CRD). A population size of 20 moths (10 males, 10 females), which was found to be most susceptible to mating disruption from prior work [42], was used in this experiment. Moths were 2-4 d old, had emerged individually in bottles from the larvae introduced, when they were individually introduced into the cubicles. After $24 \mathrm{~h}$, the moths in each cubicle were collected separately using an aspirator into conical flasks $(250 \mathrm{~mL})$. The moths were frozen at $-10^{\circ} \mathrm{C}$ for $1 \mathrm{~h} \mathrm{[62]} \mathrm{to} \mathrm{ensure} \mathrm{the} \mathrm{death} \mathrm{of} \mathrm{insects} \mathrm{as} \mathrm{well} \mathrm{as}$ the best visibility of spermatophores [63]. The mating status of moths was determined by observing the presence of spermatophores in the bursa copulatrix of female moths [64]. To accomplish this, moths were dissected under a stereomicroscope (OPTIKA, Triace, Italy). The number of female moths that were mated following each exposure was recorded. Furthermore, the number of male moths captured inside monitoring traps was determined.

Following each experiment, the entire facility and the cubicles were washed using a biodegradable detergent (Britol Disinfectant Pine, Antler Industries Pvt. Ltd., Piliyandala, Sri Lanka) to remove any pheromone residues and was allowed to air dry before the next round of experiments. Furthermore, before the next experiment, the contaminated air inside the room was removed using an exhaust fan.

\subsubsection{Recording Environmental Conditions of Cubicles}

The temperature and relative humidity profiles inside and outside the cubicles during the experiment were recorded by data loggers (TM-305U, Tenmars Electronics Co., Ltd., Taiwan). The average values of temperature and relative humidity inside and outside of the cubicles were $30 \pm 1{ }^{\circ} \mathrm{C}, 63 \pm 1 \% \mathrm{RH}$ and $32 \pm 1^{\circ} \mathrm{C}, 64 \pm 2 \% \mathrm{RH}$, respectively.

\subsubsection{Experimental Design and Data Analysis}

The experiment was conducted as a completely randomized design (CRD). Each control or treatment experiment had four replicates. Responses consisted of females (mated or unmated) and males (captured or not), which were analyzed using a generalized linear model based on a binomial distribution with a logit link function. Explanatory variables included the presence of pheromone (yes or no), botanical oils (as above), and their interaction. Overdispersion was checked and not found to be a problem. Upon a significant result from the model, $\chi^{2}$-tests with Bonferroni correction to the $p$-value were used for multiple comparisons. 


\subsection{Experiment 2. Burrowing of Cadra cautella Larvae in Different Flour Media Treated with Spinosad}

\subsubsection{Insects}

Cadra cautella larvae aged $10 \mathrm{~d}$ were used in this experiment. These larvae were obtained from C. cautella cultures reared as described in Section 2.1. For this experiment, larvae measuring approximately the same size were used.

\subsubsection{Types of Flour and Insecticide Application}

The following types of flour were purchased from a local retailer and used in the experiment: rice flour, maize flour, mung bean flour, cowpea flour and atta flour (hard wheat flour). For each replicate of the types of flour, $250 \mathrm{~g}$ of that specific flour was weighed into separate plastic sealable bags $(20 \times 30 \mathrm{~cm}$ width:length). The commercial product 'Success' (Spinosad 25 g/L SC, Hayleys Agriculture, Sri Lanka) was used as the source of spinosad. A solution with the labeled rate of $25 \mathrm{ppm}$ of spinosad was prepared by diluting the $100 \mu \mathrm{L}$ of the commercial product in $100 \mathrm{~mL}$ distilled water. Next, each replicate $250 \mathrm{~g}$ of flour weighed above was placed on a piece of aluminium foil (approx. $1 \mathrm{~mm}$ thickness). A total of $3.75 \mathrm{~mL}$ of the spinosad solution was sprayed on to each $250 \mathrm{~g}$ flour sample by using an artist's air brush (VL-202S, Paasche Airbrush Company, USA) [65]. Immediately afterwards, each flour sample was placed inside a sealable bag and hand tumbled for $1 \mathrm{~min}$. In the control treatment, each $250 \mathrm{~g}$ flour sample was instead sprayed with $3.75 \mathrm{~mL}$ of distilled water in the same way. There were four replicate flour samples from each flour type and treatment combination. For each replicate of flour type and treatment, $40 \mathrm{~g}$ of treated material was used in to determine the burrowing depth of C. cautella larvae, as described below.

\subsubsection{Introduction of Cadra cautella Larvae to Flour}

Glass vials (50mL capacity and measuring $3 \mathrm{~cm}$ diameter, $20 \mathrm{~cm}$ height) were used to assess the burrowing behavior for the experiment. The volume level filled by $40 \mathrm{~g}$ of flour without compaction was marked on the circumference of the vial (approx. at $18 \mathrm{~cm}$ from bottom). Four vertical lines in each cardinal direction, including North (A), South (B), East (C) and West (D), were marked on the circle. These points served as reference points for noting the burrowing of $C$. cautella larvae through a given type of flour. The treatments consisted of spinosad-treated (different types as mentioned in 2.3.2) or water-treated flour. Twenty C. cautella larvae $(10 \mathrm{~d}$ old $)$ were introduced into each vial. The vials were maintained inside an incubator (FH-1200 LED T8, HiPoint Laboratory, Taiwan) at $33 \pm 1{ }^{\circ} \mathrm{C}$ and $60 \pm 5 \%$ RH. In each vial, the daily average burrowing depth of $C$. cautella larvae was determined by measuring the distance burrowed from the reference points (A, B, C and D) along the vertical lines. In addition, the total cumulative burrowing depth was noted as the total cumulative distance burrowed over $10 \mathrm{~d}$.

\subsubsection{Experimental Design and Data Analysis}

The experiment was conducted as a completely randomized design (CRD). Each treatment or control experiment had four replicates. Differences in the cumulative burrowing depths of C. cautella larvae in different types of flour were analyzed by using ANOVA procedures of statistical analysis system (SAS) [66] with mean separation by Tukey's test and significance at $\alpha=0.05$.

\section{Results}

3.1. Experiment 1. Response of Cadra cautella to Sex Pheromone Components (Z, E)-9, 12-tetradecadienyl Acetate and (Z)-9-tetradecadien-1-yl Acetate in the Presence of Botanicals

The presence of pheromone (GLM: $\left.\chi^{2}=38.0, \mathrm{df}=1, p<0.0001\right)$, but not the botanical oils alone $\left(\chi^{2}=2.14, \mathrm{df}=6, p=0.14\right)$, significantly affected the number of mated females (Figure 1). In general, the percentage of mated females was significantly higher in the botanical oil only controls than the botanical oil + pheromone treatment (interaction: $\chi^{2}=15.8, \mathrm{df}=6, p<0.01$ ) (Figure 1). There were 
no significant differences in the percentage of mated females among the different botanical oils when tested alone. When the botanical oils were combined with pheromone, the percentage of mated females was higher in the presence of camphor oil $(57.5 \pm 2.5 \%)$, citronella oil $(55 \pm 5.0 \%)$ and neem oil $(42.5 \pm 2.5 \%)$ compared with sandalwood oil $(30 \pm 4.08 \%)$ and mee oil $(15 \pm 2.89 \%)$. The percentage of mated females in cinnamon oil $(37.5 \pm 2.5 \%)$ was in-between these two categories. Mating success was not different among sandalwood oil, mee oil and cinnamon oil when compared to the control treatment $(12.5 \pm 2.5 \%)$, which used the pheromone blend only. Neither the presence of pheromone $\left(\chi^{2}=1.39, \mathrm{df}=1, p=0.24\right)$, the botanical oils $\left(\chi^{2}=7.78, \mathrm{df}=6, p=0.25\right)$, nor their interaction $\left(\chi^{2}=10.8\right.$, $\mathrm{df}=6, p=0.09$ ) affected male attraction (Figure 2).

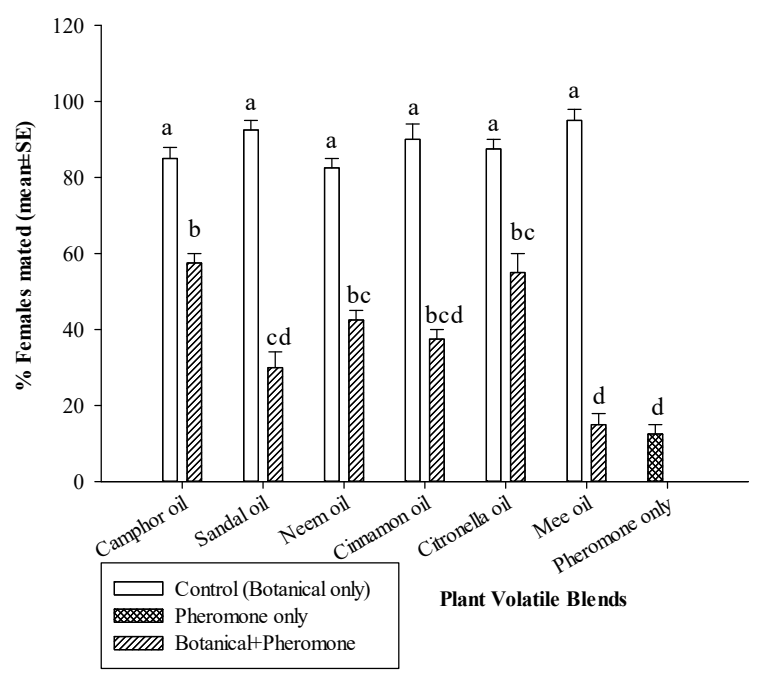

Figure 1. Percentage (mean $\pm \mathrm{SE}$ ) of mated C. cautella females following exposure to plant volatiles (e.g., botanical oils) only (white bars), pheromone only (hatched bars), or both together (diagonal lined bars) $(n=4)$. Means followed by the same letter are not significantly different (Tukey's test following ANOVA, $\alpha=0.05)$.

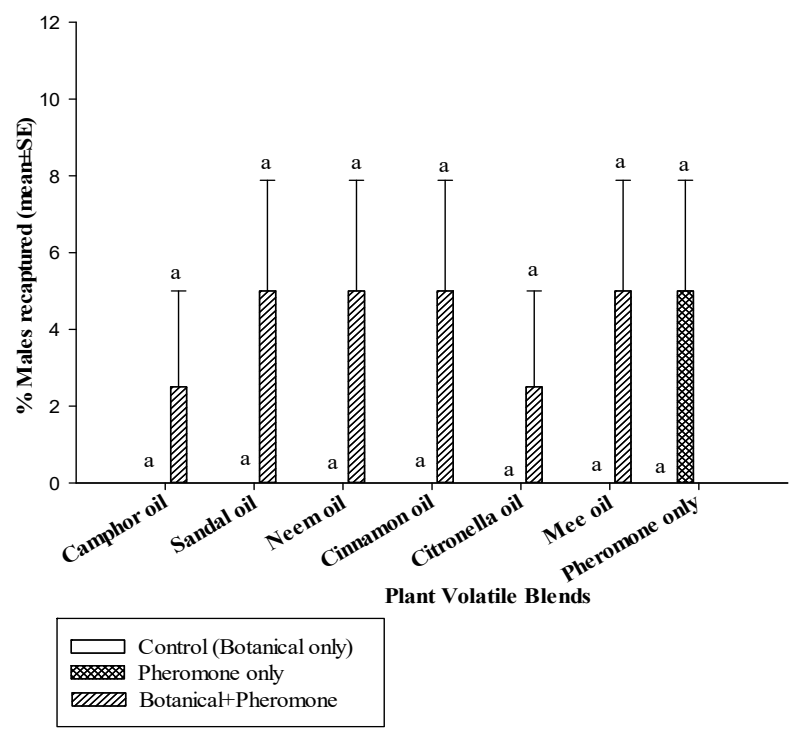

Figure 2. Percentage (mean $\pm \mathrm{SE}$ ) of $C$. cautella males attracted to plant volatiles (e.g., botanicals) only (white bars), pheromone only (hatched bars), or both together (diagonal lined bars) expressed as a percentage of those released that were recaptured ( $n=4$ per bar). All the treatments using botanical oil only had no males captured ( $0 \%$ of total released). Means followed by the same letter are not significantly different (Tukey's test following ANOVA, $\alpha=0.05$ ). 


\subsection{Experiment 2. Burrowing of Cadra cautella Larvae in Different Types of Flours Treated with Spinosad}

In all the flour types, the burrowing of $C$. cautella larvae gradually increased as more time elapsed. In the water-treated controls, the burrowing depth varied from $0.36 \pm 0.02 \mathrm{~cm}$ (atta flour) to $2.04 \pm 0.15 \mathrm{~cm}$ (maize flour). In the spinosad-treated flour, the minimum and maximum burrowing depths were $0.69 \pm 0.02 \mathrm{~cm}$ (atta flour) and $3.2 \pm 0.14 \mathrm{~cm}$ (rice flour), respectively. Overall, the burrowing of $C$. cautella larvae was higher in the spinosad-treated flour than their water-treated controls, except for maize flour $\left(\mathrm{F}_{9,30}=85.2, p<0.0001\right)$ (Table $\mathrm{S1}$ ). In maize flour, C. cautella burrowed a 1.3-1.6-fold greater depth in the water-treated control than in the spinosad-treated flour, regardless of the duration.

In rice flour, mung bean flour and cowpea flour, there was a significant difference in the burrowing depth between the spinosad-treated and water-treated flour (Table S1). Specifically, larvae burrowed 2.3-4.1-fold, 2.1-2.0-fold, and 1.9-2.2-fold more in spinosad-treated compared to water-treated rice, mung bean, and cowpea flour, respectively. In maize flour and atta flour, there were no significant differences observed between the spinosad-treated and control.

\section{Discussion}

The mate-finding behavior of lepidopterans mainly depends on males following sex pheromone plumes to their point source (e.g., females) [67,68]. Nansen and Phillips [69] found that many of the botanical oils enhanced the oviposition of Plodia interpunctella (Hübner) (Lepidoptera: Pyralidae), the Indianmeal moth, including olive, sunflower and corn oils. Previous work has found that plant volatiles stimulate the release of the female ermine moth's sex pheromones to attract males (e.g., Yponomeuta) [70]. In this study, we found that a greater percentage of C. cautella successfully mated in the presence of camphor oil, citronella oil and neem oil, which supports prior findings that plant volatiles may modulate mating success among moths. These studies have shown that plant volatiles may synergize attraction to their natural sex pheromones [69-73]. In this case, decreased mating disruption efficacy may be because of an effect by botanical oils on (1) males, (2) females, or (3) both sexes. In future work, the specific target sex behavior and mechanism should be investigated in order to deliver a better understanding of how these biorational approaches may interact with each other. While we used a 5:1 ratio of ZETA:ZTA in this study, the natural ratio produced for these by C. cautella is 14:1; addition of botanical oils could have changed the effective concentration of the lure in the cubicles, with ramifications for mate-finding. In other systems, there may be reduced responses to pheromone after exposure to plant or non-host volatiles some non-Lepidopteran taxa, as was shown to be the case with Dendroctonus frontalis LeConte (Coleoptera: Scolytidae), the southern pine beetle, following exposure to 4-allyl anisole in Loblolly pine (Pinus taeda), and for some other bark beetle species [74-76]. Nonetheless, in the laboratory setting evaluated here, the use of botanical oils for control of stored product lepidoptera may inadvertently circumvent other pest management tactics, such as mating disruption. Future research should explore this behavioral phenomenon at a semi-field and larger scale, as well as explore the mechanisms that enhance the mating in C. cautella following exposure to plant volatiles, considering multiple tactics together may have important implications for their implementation for food facilities.

The chemical $(\mathrm{Z}, \mathrm{E})-9,12$-tetradecadienyl acetate secreted by $C$. cautella is also emitted by the unrelated taxon Spodoptera exigua (Hübner) (Lepidoptera: Noctuidae), the beet armyworm. The plant volatiles linalool and myrcenebenzaldehyde have been shown to increase the response of male S. exigua to their natural sex pheromone [75]. However, we found no evidence to support increased male attraction in the presence of plant volatiles, at least for the specific botanical oils tested. It is possible that individual components in the headspace blends from the botanical oils may be behaviorally antagonistic, which results in a net effect of no response, as has been shown for other species such as the invasive spotted-wing drosophila, Drosophila suzukii (Matsumura) (Diptera: Drosophilidae) [77]. It may be useful to test the behavioral effects of individual volatiles instead of blends produced by the botanical oils, or at least screen the volatiles in the blends produced by the botanical oils with electroantennography coupled with gas chromatography. 
The current study revealed that C. cautella readily burrowed in different types of flour. Prior to this work, little information was available on the burrowing ability of $C$. cautella larvae through different commodities. Bell [78] and Mullen et al. [79] showed that mature C. cautella larvae will wander in the food and may bore through packaging material. It has also been documented that C. cautella larvae can penetrate through a variety of packing materials, such as cellophane, polyethylene, paper material, polyvinylchloride and polypropylene films [80-82]. P. interpunctella, a closely related lepidopteran species that shares certain behavioural characteristics with C. cautella [16] is also able to penetrate through polyethylene $[83,84]$, but this ability differs with the age of larvae $[81,82,85]$ and the thickness of material [82,85]. By contrast, larvae of P. interpunctella and Trogoderma variabile Ballion (Coleoptera: Dermestidae) cannot penetrate through methoprene-treated foil packaging [84]. Some other studies have revealed that the few warehouse beetle T. variabile larvae that were able to penetrate methoprene-treated foil experienced deformities in the adult stage [86]. The use of packaging as a cultural control tactic for $C$. cautella may be worth considering in combination with behaviorally based tactics, such as mating disruption and other biorational strategies in future research.

Our study has shown that spinosad-treated flour results in elevated burrowing activity for C. cautella larvae compared with water-treated controls. This suggests that burrowing behavior by C. cautella is flexible and inducible, and may result in behavioral resistance to the use of contact insecticides, whereby larvae will escape by seeking out refugia deeper in commodities. This may severely curtail the actual efficacy of contact or residual insecticides when used to treat sites of spillage or bulk commodities with existing infestations of $C$. cautella. Furthermore, unless commodities are thoroughly examined during cleaning and remedial actions, C. cautella infestation may continue unabated until the population increases to higher levels and flying adults emerge. Furthermore, burrowing might negatively affect the pheromone and kairomone-baited trapping of conspecific C. cautella when contact insecticides are used in a food facility, because their application will push individuals further into commodities. However, adult moths will likely not be affected, so monitoring in long-standing infestations or for flight activity traps may not be impacted. Future experiments need to investigate the interaction between contact insecticides and monitoring for $C$. cautella.

The current study found how the burrowing behavior of $C$. cautella larvae is affected by spinosad. It was also found that once adults emerged, their mating can be disrupted by exposure to pheromone and botanical oils used either alone or in combination. Previous work has shown how C. cautella larvae can be controlled by spinosad [42]. Even if C. cautella larvae seek refuge in flour treated with spinosad, and thus escape monitoring, their population can still be managed once they emerge as adults by using pheromones, botanicals or their combination as highlighted in the current work. Overall, this work illuminates the behavior and mating of $C$. cautella, and particularly how it is influenced by biorational pest management strategies. This information may be used for protecting stored food from infestation by this devastating pest.

\section{Conclusions}

In conclusion, camphor oil, citronella oil and neem oil increase the mating success of $C$. cautella in the presence of the synthetic sex pheromone. The burrowing depth of $C$. cautella larvae varies with the type of flour, but generally is increased in spinsoad-treated flour compared to controls for rice, mung bean, and cowpea flour.

Supplementary Materials: The following are available online at http://www.mdpi.com/2075-4450/11/12/845/s1, Table S1: Cumulative burrowing depth (mean \pm SE) by Cadra cautella larvae over 10 days through different flour media treated with spinosad $(n=4)$.

Author Contributions: Conceptualization, A.M.P.S. and L.K.W.W.; methodology, L.K.W.W.; software, L.K.W.W.; validation, L.K.W.W.; formal analysis, A.M.P.S.; investigation, A.M.P.S. and D.M.S.K.D.; resources, L.K.W.W.; data curation, A.M.P.S.; writing—original draft preparation, A.M.P.S.; writing—review and editing, L.K.W.W., T.C.B., W.R.M.III; visualization, L.K.W.W.; supervision, L.K.W.W.; project administration, L.K.W.W.; funding acquisition, L.K.W.W. All authors have read and agreed to the published version of the manuscript. 
Funding: This research was funded by the research grant NARP/16/RUSL/AG/01. The authors are thankful to the Sri Lanka Council for Agricultural Research Policy (SLCARP) for providing funds through the above research grant. Publication of this work was funded, in part, by a United States Department of Agriculture (USDA), National Institute of Food and Agriculture (NIFA), Crop Protection and Pest Management (CPPM) Grant \#2017-70006-27262 issued to W.R.M.

Acknowledgments: The use of trade names is for the purposes of providing scientific information only, and does not constitute endorsement by the United States Department of Agriculture (USDA). The USDA is an equal opportunity employer.

Conflicts of Interest: The authors declare no conflict of interest. The funders had no role in the design of the study; in the collection, analyses, or interpretation of data; in the writing of the manuscript, or in the decision to publish the results.

\section{References}

1. United Nations, Department of Economic and Social Affairs, Population Division. World Population Prospects: The 2017 Revision, Key Findings and Advance Tables. Working Paper No. ESA/P/WP/248. 2017. Available online: https://www.un.org/development/desa/publications/world-population-prospects-the-2017revision.html (accessed on 12 May 2020).

2. Kumar, D.; Kalita, P. Reducing postharvest losses during storage of grain crops to strengthen food security in developing countries. Foods 2017, 6, 8. [CrossRef] [PubMed]

3. Wijayaratne, L.K.W.; Rajapakse, R.H.S. Effects of spinosad on the heat tolerance and cold tolerance of Sitophilus oryzae L. (Coleoptera: Curculionidae) and Rhyzopertha dominica F. (Coleoptera: Bostrichidae). J. Stored Prod. Res. 2018, 77, 84-88. [CrossRef]

4. Wijayaratne, L.K.W.; Fernando, M.D.; Palipane, K.B. Control of insect pests under ware- house conditions using smoke generated from partial combustion of rice (paddy) husk. J. Natl. Sci. Found. 2009, 37, 125-134. [CrossRef]

5. Dissanayaka, D.M.S.K.; Sammani, A.M.P.; Wijayaratne, L.K.W.; Samaranayaka, P.M.; Karunarathna, L.M.; Chandima, N.; Wijerathna, I.M.; Harshana, S.; Heshani, A.; Kalhari, D. Postharvest losses of agricultural commodities in Trincomalee, Sri Lanka. In Proceedings of the 12th International Working Conference on Stored Product Protection, Berlin, Germany, 11 October 2018; Adler, C.S., Opit, G., Furstenau, B., Muller-Blenkle, C., Kern, P., Arthur, F.H., Athanassiou, C.G., Bartosik, R., Campbell, J., Carvalho, M.O., et al., Eds.; Julius Kühn-Institut: Berlin, Germany, 2018; pp. 55-57.

6. Kumari, J.M.P.; Wijayaratne, L.K.W.; Jayawardena, N.W.I.A.; Egodawatta, W.C.P. Quantitative and qualitative losses in paddy, maize and green gram stored under household conditions in Anuradhapura district of Sri Lanka. Sri Lankan J. Agri. Ecosys. 2020, 2, 99-106. [CrossRef]

7. Sajeewani, P.A.H.; Karunarathne, E.V.U.P.; Wijerathne, K.B.T.T.; Mahalekam, M.P.S.; Rupasinghe, M.D.M.C.; Dissanayaka, D.M.S.K.; Wijayaratne, L.K.W.; Sammani, A.M.P. Abundance of insects in rice mills in Polonnaruwa, Sri Lanka. In Proceedings of the 12th International Working Conference on Stored Product Protection, Berlin, Germany, 11 October 2018; Adler, C.S., Opit, G., Furstenau, B., Muller-Blenkle, C., Kern, P., Arthur, F.H., Athanassiou, C.G., Bartosik, R., Campbell, J., Carvalho, M.O., et al., Eds.; Julius Kühn-Institut: Berlin, Germany, 2018; pp. 57-58.

8. Sajeewani, P.A.H.; Dissanayaka, D.M.S.K.; Wijayaratne, L.K.W. Progeny production by Stegobium paniceum (L.) (Coleoptera: Anobiidae) (drugstore beetle) in different spices. Rajarata Univ. J. 2020, 5, 13-17.

9. Wijayaratne, L.K.W.; Dissanayaka, D.M.S.K.; Sammani, A.M.P. Variation in Rhyzopertha dominica (F.) (Coleoptera: Bostrychidae) progeny adult emergence in different animal feed stored under ventilated and non-ventilated conditions. J. Stored Prod. Res. 2019, 84, 101516. [CrossRef]

10. Adhikarinayake, T.B.; Palipane, K.B.; Muller, J. Quality change and mass loss of paddy during airtight storage in a ferro-cement bin in Sri Lanka. J. Stored Prod. Res. 2006, 42, 377-390. [CrossRef]

11. Hill, D.S. Types of damage. In Pests of Stored Products and Their Control; Belhaven Press: London, UK, 1990.

12. Arbogast, R.T.; Chini, S.R. Erratum to abundance of Plodia interpunctella (Hubner) and Cadra cautella (Walker) infesting maize stored on South Carolina farms: Seasonal and non-seasonal variation. J. Stored Prod. Res. 2005, 41, 528-543. [CrossRef]

13. Hagstrum, D.W.; Subramanyam, B. Fundamentals of Stored-Product Entomology; AACC International: St Paul, MN, USA, 2006. 
14. Ahmed, M. Disinfestation of stored grains, pulses, dried fruits and nuts, and other dried foods. In Food Irradiation: Principles and Applications; Molins, R.A., Ed.; John Wiley \& Sons: New York, NY, USA, 2001.

15. Savoldelli, S.; Süss, L. Integrated control of Ephestia cautella (Walker) in a confectionary factory. In Proceedings of the 10th International Working Conference on Stored-Product Protection (IWCSPP), Berlin, Germany, 27 June-2 July 2010; Carvalho, M.O., Fields, P.G., Adler, C.S., Arthur, F.H., Athanassiou, C.G., Campbell, J.F., Fleurat-Lessard, F., Flinn, P.W., Hodges, R.J., Isikber, A.A., et al., Eds.; Julius-Kühn-Archiv: Berlin, Germany, 2010; pp. 991-992.

16. Burks, C.S.; Johnson, J.A. Biology, behavior, and ecology of stored fruit and nut insects. In Stored Product Protection; Hagstrum, D.W., Phillips, T.W., Cuperus, G., Eds.; Kansas State University: Manhattan, KS, USA, 2012; pp. 21-32.

17. Edde, P.A.; Eaton, M.; Kells, S.A.; Phillips, T.W. Biology, behavior, and ecology of pests in other durable commodities. In Stored Product Protection; Hagstrum, D.W., Phillips, T.W., Cuperus, G., Eds.; Kansas State University: Manhattan, KS, USA, 2012; pp. 45-62.

18. Mason, L.J.; McDonough, M. Biology, behavior, and ecology of stored grain and legume insects. In Stored Product Protection; Hagstrum, D.W., Phillips, T.W., Cuperus, G., Eds.; Kansas State University: Manhattan, KS, USA, 2012; pp. 7-20.

19. Arthur, F.H.; Starkus, L.A.; McKay, T. Degradation and residual efficacy of beta-cyfluthrin as a surface treatment for control of Tribolium castaneum Herbst: Effects of temperature and environment. J. Stored Prod. Res. 2019, 84, 101514. [CrossRef]

20. Ridley, A.W.; Burrill, P.R.; Cook, C.C.; Daglish, G.J. Phosphine fumigation of silo bags. J. Stored Prod. Res. 2011, 47, 349-356. [CrossRef]

21. Fields, P.G. Comparison of efficacy of methyl bromide and sulfuryl fluoride fumigations in Canadian pasta plants. In Proceedings of the Ninth International Controlled Atmosphere and Fumigation in Stored Products, Antalya, Turkey, 15-19 October 2012; Navarro, S., Banks, H.J., Jayas, D.S., Bell, C.H., Noyes, R.T., Ferizli, A.G., Emekci, M., Isikber, A., Alagusundaram, K., Eds.; ARBER Professional Congress Services: Antalya, Turkey, 2012; pp. 215-221.

22. Hwaidi, M.I.; Collins, P.J.; Sissons, M. Does sorption of sulfuryl fluoride by wheat reduce its efficacy against adults and eggs of Rhyzopertha dominica? J. Stored Prod. Res. 2017, 74, 91-97. [CrossRef]

23. Beckett, S.J. Insect and mite control by manipulating temperature and moisture before and during chemical-free storage. J. Stored Prod. Res. 2011, 47, 284-292. [CrossRef]

24. Arthur, F.H.; Hartzer, K.L.; Throne, J.E.; Flinn, P. Susceptibility of Tribolium castaneum (Coleoptera: Tenebrionidae) and Trogoderma inclusum (Coleoptera: Dermestidae) to cold temperatures. J. Stored Prod. Res. 2015, 64, 45-53. [CrossRef]

25. Obeng-Ofori, D. The use of botanicals by resource poor farmers in Africa and Asia for the protection of stored agricultural products. Stewart Postharvest Rev. 2007, 6, 1-8. [CrossRef]

26. Arthur, F.H. Grain protectants: Current status and prospects for the future. J. Stored Prod. Res. 1996, 32, 293-302. [CrossRef]

27. Phillips, T.W.; Throne, J.E. Biorational approaches to managing stored product insects. Annu. Rev. Entomol. 2010, 55, 375-397. [CrossRef] [PubMed]

28. Opit, G.P.; Phillips, T.W.; Aikins, M.J.; Hasan, M.M. Phosphine resistance in Tribolium castaneum and Rhyzopertha dominica from stored wheat in Oklahoma. J. Econ. Entomol. 2012, 105, 1107-1114. [CrossRef]

29. Wijayaratne, L.K.W.; Arthur, F.H.; Whyard, S. Methoprene and control of stored-product insects. J. Stored Prod. Res. 2018, 76, 161-169. [CrossRef]

30. Morrison, W.R., III; Larson, N.L.; Brabec, D.; Zhang, A. Methyl benzoate as a putative alternative, environmentally-friendly fumigant for the control of stored product insects. J. Econ. Entomol. 2019, 112, 2458-2468. [CrossRef]

31. Morrison, W.R., III; Bruce, A.; Wilkins, R.V.; Albin, C.E.; Arthur, F.H. Sanitation improves stored product insect pest management. Insects 2019, 10, 77. [CrossRef]

32. Subramanyam, B.; Roesli, R. Inert dusts. In Alternatives to Pesticides in Stored-Product IPM; Subramanyam, B., Hagstrum, D.W., Eds.; Kluwer Academic Publishers: Dordrecht, The Netherlands, 2000; pp. 321-380.

33. Morrison, W.R., III; Cullum, J.P.; Leskey, T.C. Evaluation of trap designs and deployment strategies for capturing Halyomorpha halys (Hemiptera: Pentatomidae). J. Econ. Entomol. 2015, 108, 1683-1692. [CrossRef] 
34. Morrison, W.R., III; Lee, D.H.; Short, B.D.; Khrimian, A.; Leskey, T.C. Establishing the behavioral basis for an attract-and-kill strategy to manage the invasive Halyomorpha halys in apple orchards. J. Pest. Sci. 2016, 89, 81-86. [CrossRef]

35. Ahmad, T.R. Effects of pheromone trap design and placement on capture of almond moth, Cadra cautella (Lepidoptera: Pyralidae). J. Econ. Entomol. 1987, 80, 897-900. [CrossRef]

36. Ryne, C.; Ekeberg, M.; Jonzen, N.; Oehlschlager, C.; Lofstedt, C.; Anderbrant, O. Reduction in an almond moth Ephestia cautella (Lepidoptera: Pyralidae) population by means of mating disruption. Pest Manag. Sci. 2006, 62, 912-918. [CrossRef] [PubMed]

37. Plarre, R. More than a pest management tool -45 years of practical experience with insect pheromones in stored-product and material protection. J. Plant Dis. Protect. 2013, 120, 145-152. [CrossRef]

38. Allison, J.; Cardé, R. Bidirectional selection for novel pheromone blend ratios in the almond moth, Cadra cautella. J. Chem. Ecol. 2007, 33, 2293-2307. [CrossRef] [PubMed]

39. Read, J.S.; Haines, C.P. The functions of the female sex pheromones of Ephestia cautella (Walker) (Lepidoptera, Phycitidae). J. Stored Prod. Res. 1976, 12, 49-53. [CrossRef]

40. Prevett, P.F.; Benton, F.P.; Hall, D.R.; Hodges, R.J.; dos Serodio, S.R. Suppression of mating in Ephestia cautella (Walker) (Lepidoptera: Phycitidae) using microencapsulated formulations of synthetic sex pheromone. J. Stored Prod. Res. 1989, 25, 147-154. [CrossRef]

41. Pease, G.; Storm, C.G. Efficacy of pheromone-based control system, Exosex ${ }^{\mathrm{TM}}$ SPTab, against moth pests in European food processing facilities. In Proceedings of the 10th International Working Conference on Stored-Product Protection (IWCSPP), Berlin, Germany, 27 June-2 July 2010; Carvalho, M.O., Fields, P.G., Adler, C.S., Arthur, F.H., Athanassiou, C.G., Campbell, J.F., Fleurat-Lessard, F., Flinn, P.W., Hodges, R.J., Isikber, A.A., et al., Eds.; Julius-Kühn-Archiv: Berlin, Germany, 2010; pp. 183-189.

42. Sammani, A.M.P.; Dissanayaka, D.M.S.K.; Wijayaratne, L.K.W.; Morrison, W.R., III. Effects of spinosad and spinetoram on larval mortality, adult emergence, progeny production and mating in Cadra cautella (Walk.) (Lepidoptera: Pyralidae). J. Stored Prod. Res. 2020, 88, 101665. [CrossRef]

43. Rajapakse, R.H.S. Effect of five botanicals as protectants of green gram against the pulse beetle Callosobruchus maculatus. In Proceedings of the Second International Symposium on Bruchids and Legumes, Okayama, Japan, 1 July 1990; Fujii, K., Gatehouse, A.M.R., Johnson, C.D., Mitchel, R., Yoshida, T., Eds.; Kluwer Academic Publishers: Okayama, Japan, 1990; pp. 85-90.

44. Rajapakse, R.H.S.; Van Emden, H.F. Potential of four vegetable oils and ten botanical powders for reducing infestation of cowpeas by Callosobruchus maculatus, C. Chinensis and C. rhodesianus. J. Stored Prod. Res. 1997, 33, 59-68. [CrossRef]

45. Rajapakse, R.H.S. Pesticidal potential of tropical plants-insecticidal activity of some selected natural products against Callosobruchus maculatus and C. chinensis. Proc. Entomo. Congress, Trivandrum India. 2000, 11, 69-71.

46. Belmain, S.R.; Neal, G.E.; Ray, D.E.; Golob, P. Insecticidal and vertebrate toxicity associated with ethno botanicals used as post-harvest protectants in Ghana. Food Chem. Toxicol. 2001, 39, 287-291. [CrossRef]

47. Said, P.; Pashte, V. Botanicals: The protectants of stored grains pests. Trends Biosci. 2015, 8, 3750-3755.

48. Lal, M.; Ram, B.; Tiwari, P. Botanicals to cope stored grain insect pests: A review. Int. J. Curr. Microbiol. Appl. Sci. 2017, 6, 1583-1594. [CrossRef]

49. Dissanayaka, D.M.S.K.; Sammani, A.M.P.; Wijayaratne, L.K.W. Food oils as kairomones for trapping Tribolium castaneum (Herbst) (Coleoptera: Tenebrionidae) adults. J. Stored Prod. Res. 2018, 79, 83-88. [CrossRef]

50. Singh, B.; Kaur, A. Control of insect pests in crop plants and stored food grains using plant saponins: A review. LWT Food Sci. Technol. 2018, 87, 93-101. [CrossRef]

51. Allotey, J.; Goswami, L. Damage caused and control of the moths Plodia interpunctella (Hubn.) and Ephestia cautella (Wlk.) on maize and groundnuts using local plant materials. Insect Sci. Appl. 1994, 15, 323-329. [CrossRef]

52. Rajendran, S. Insect infestation and control in stored grain sorghum and millets. Int. J. Food Sci. Tech. 2003, 40, 451-457.

53. Klerkx, L.; van Mierlo, B.; Leeuwis, C. Evolution of systems approaches to agricultural innovation: Concepts, analysis and interventions. In Farming Systems Research into the 21st Century; Darnhofer, I., Gibbon, D., Dedieu, B., Eds.; The New Dynamic, Springer: Dordrecht, The Netherlands, 2012.

54. Rentokil. Common Species of Pests in Food (C) 2020 Rentokil Initial plc. 2020. Available online: https: //www.rentokil.tt/pests-in-food/species (accessed on 25 April 2020). 
55. Subramanyam, B.; Hartzer, M.; Boina, D.R. Performance of pre-commercial release formulations of spinosad against five stored-product insect species on four stored commodities. J. Pest Sci. 2012, 85, 331-339. [CrossRef]

56. Athanassiou, C.G.; Kavallieratos, N.G.; Yiatilis, A.E.; Vayias, B.J.; Mavrotas, C.S.; Tomanovic, Z. Influence of temperature and humidity on the efficacy of spinosad against four stored-grain beetle species. J. Insect Sci. 2008, 8, 1-9. [CrossRef] [PubMed]

57. Hertlein, M.B.; Thompson, G.D.; Subramanyam, B.; Athanassiou, C.G. Spinosad: A new natural product for stored grain protection. J. Stored Prod. Res. 2011, 47, 131-146. [CrossRef]

58. Dissanayaka, D.M.S.K.; Sammani, A.M.P.; Wijayaratne, L.K.W. Orientation of Tribolium castaneum (Herbst) (Coleoptera: Tenebrionidae) adults at various distances to different concentrations of aggregation pheromone 4,8-dimethyldecanal. J. Stored Prod. Res. 2020, 87, 101631. [CrossRef]

59. Dissanayaka, D.M.S.K.; Sammani, A.M.P.; Wijayaratne, L.K.W. Response of different population sizes to traps and effect of spinosad on the trap catch and progeny adult emergence in Tribolium castaneum (Herbst) (Coleoptera: Tenebrionidae). J. Stored Prod. Res. 2020, 86, 101576. [CrossRef]

60. Zhu, J.W.; Ryne, C.; Unelius, C.R.; Valeur, P.G.; Lofstedt, C. Reidentification of the female sex pheromone of the Indian meal moth, Plodia interpunctella: Evidence for a four-component pheromone blend. Entomol. Exp. Appl. 1999, 92, 137-146. [CrossRef]

61. Wijayaratne, L.K.W.; Burks, C.S. Persistence of mating suppression of the Indian Meal Moth Plodia Interpunctella in the presence and absence of commercial mating disruption dispensers. Insects 2020, 11, 701. [CrossRef]

62. Ryne, C.; Svensson, G.P.; Lofstedt, C. Mating disruption of Plodia interpunctella in small-scale plots: Effects of pheromone blend, emission rates and population density. J. Chem. Ecol. 2001, 27, 2109-2124. [CrossRef]

63. Drummond, B.A. Multiple mating and sperm competition in the Lepidoptera. In Sperm Competition; Smith, R.L., Ed.; Academic Press: London, UK, 1984; pp. 291-370.

64. Mafra-Neto, A.; Baker, T.C. Timed, metered sprays of pheromone disrupt mating of Cadra cautella (Lepidoptera: Pyralidae). J. Agric. Entomol. 1996, 13, 149-168.

65. Vayias, B.J.; Athanassiou, C.G.; Milonas, D.N.; Mavrotas, C. Persistence and efficacy of spinosad on wheat, maize and barley grains against four major stored product pests. J. Crop Prot. 2010, 29, 496-505. [CrossRef]

66. SAS Institute. The SAS system for windows, Release 9.1; Statistical Analysis System Institute: Cary, NC, USA, 2002-2008.

67. Sakuma, M. Virtual reality experiments on a digital servosphere: Guiding male silkworm moths to a virtual odour source. Comput. Electron. Agric. 2002, 35, 243-254. [CrossRef]

68. Willis, M.A.; Avonder, J.L.; Zheng, E. The role of vision in odor-plume tracking by walking and flying insects. J. Exp. Biol. 2011, 214, 4121-4132. [CrossRef]

69. Nansen, C.; Phillips, T.W. Ovipositional responses of the Indianmeal moth, Plodia interpunctella (Hübner) (Lepidoptera: Pyralidae) to oils. Ann. Entomol. Soc. Am. 2003, 96, 524-531. [CrossRef]

70. Hendrikse, A.; Vos-Bunnemeyer, E. Role of host-plant stimuli in sexual behaviour of small ermine moths (Yponomeuta). Ecol. Entomol. 1987, 12, 363-371. [CrossRef]

71. Landolt, P.J.; Reed, H.C.; Heath, R.R. Attraction of female papaya fruit fly (Diptera: Tephritidae) to male pheromone and host fruit. Environ. Entomol. 1992, 21, 1154-1159. [CrossRef]

72. Nakamuta, K.; Leal, W.S.; Nakashima, T.; Tokoro, M.; Ono, M.; Nakanishi, M. Increase of trap catches by a combination of male sex pheromones and floral attractant in longhorn beetle, Anaglyptus subfasciatus. J. Chem. Ecol. 1997, 23, 1635-1640. [CrossRef]

73. Reddy, G.V.P.; Guerrero, A. Behavioral responses of the diamondback moth, Plutella xylostella, to green leaf volatiles of Brassica oleracea subsp. capitata. J. Agric. Food Chem. 2000, 48, 6025-6029. [CrossRef]

74. Hayes, J.L.; Strom, B.L.; Roton, L.M.; Ingram, L.L. Repellent properties of the host compound4-allylanisole to the southern pine beetle. J. Chem. Ecol. 1994, 20, 1595-1615. [CrossRef]

75. Dickens, J.C.; Billings, R.F.; Payne, T.L. Green leaf volatiles interrupt aggregation pheromone response in bark beetles infesting southern pines. Experientia 1992, 48, 523-524. [CrossRef]

76. Poland, T.M.; Borden, J.H.; Stock, A.J.; Chong, L.J. Green leaf volatiles disrupt responses by the spruce beetle, Dendroctonus rufipennis, and the western pine beetle Dendroctonus brevicomis (Coleoptera: Scolytidae) to attractant-baited traps II. J. Entomol. Soc. B.C. 1998, 95, 17-24. 
77. Cha, D.H.; Adams, T.; Rogg, H. Identification and field evaluation of fermentation volatiles from wine and vinegar that mediate attraction of spotted wing drosophila, Drosophila szuukii. J. Chem. Ecol. 2012, 38, 1419-1431. [CrossRef]

78. Bell, C.H. Insect and mite penetration and contamination of packaged foods. In Food and Beverage Stability and Shelf Life; Woodhead Publishing: Sawston, UK, 2011; pp. 106-131.

79. Mullen, M.A.; Vardeman, J.M.; Bagwell, J. Fumigation. In Stored Product Protection; Hagstrum, D.W., Phillips, T.W., Cuperus, G., Eds.; Kansas State University: Manhattan, KS, USA, 2012; pp. 157-178.

80. Cline, L.D. Clinging and climbing ability of larvae of eleven species of stored-product insects on nine flexible packaging materials and glass. J. Econ. Entomol. 1978, 71, 689-691. [CrossRef]

81. Cline, L.D. Penetration of seven common flexible packaging materials by larvae and adults of eleven species of stored-product insects. J. Econ. Entomol. 1978, 71, 726-729. [CrossRef]

82. Bowditch, T.G. Penetration of polyvinyl chloride and polypropylene packaging films by Ephestia cautella (Lepidoptera: Pyralidae) and Plodia interpunctella (Lepidoptera: Pyralidae) larvae, and Tribolium confusum (Coleoptera: Tenebrionidae) adults. J. Econ. Entomol. 1997, 90, 1028-1031. [CrossRef]

83. Shinoda, K.; Tanaka, S.; Yoshida, T.; Nakasuji, F. Penetration of polyethylene film for packaging by larvae of Indian meal moth, Plodia interpunctella (Hübner) (Lepidoptera: Pyralidae) and their dispersal. Jpn. J. Appl. Entomol. Z. 1990, 2, 128-132.

84. Scheff, D.S.; Sehgal, B.; Subramanyam, B. Evaluating Penetration Ability of Plodia interpunctella (Hubner) (Lepidoptera: Pyralidae) Larvae into Multilayer Polypropylene Packages. Insects 2018, 9, 42. [CrossRef]

85. Tsuji, H. Experimental invasion of a food container by first-instar larvae of the Indian meal moth, Plodia internpuctella Hübner, through pinholes. Med. Entomol. Zool. 1998, 49, 99-104. [CrossRef]

86. Scheff, D.S.; Subramanyam, B.; Arthur, F. Effect of methoprene treated polymer packaging on fecundity, egg hatchability, and egg-to-adult emergence of Tribolium castaneum and Trogoderma variabile. J. Stored Prod. Res. 2016, 69, 227-234. [CrossRef]

Publisher's Note: MDPI stays neutral with regard to jurisdictional claims in published maps and institutional affiliations.

(C) 2020 by the authors. Licensee MDPI, Basel, Switzerland. This article is an open access article distributed under the terms and conditions of the Creative Commons Attribution (CC BY) license (http://creativecommons.org/licenses/by/4.0/). 